\title{
Intentionality and Partial Belief
}

\author{
Weng Hong Tang
}

\section{Introduction}

Suppose we wish to provide a naturalistic account of intentionality. Like several philosophers, we focus on the intentionality of belief, hoping that we may later supplement our account to accommodate other intentional states such as desires and fears. Now suppose that we also take partial beliefs or credences seriously. In cashing out our favoured theory of intentionality, we may for the sake of simplicity talk as if belief is merely binary or all-or-nothing. But we should be able to supplement or modify our account to accommodate credences. I'll argue, however, that it is difficult to do so with respect to certain causal or teleological theories of intentionality - in particular, those advanced by the likes of Robert Stalnaker (1984) and Ruth Millikan (1989). ${ }^{1}$

What do I mean by taking credences seriously? At the minimum, it is to hold that the notion of credence is coherent. It is also to deny that talk of credence can be replaced by talk of binary beliefs about objective probabilities - to deny that, for any $x$ in the interval $[0,1]$, to have a credence of $x$ in $p$ is just to have a binary belief that the objective probability that $p$ is true is $x .^{2}$ However, taking

\footnotetext{
${ }^{1}$ I'll not try to show that all causal or teleological theories of intentionality have difficulty accommodating credences. My focus is on those that attempt to account for the intentionality of belief directly. There are other causal or teleological theories that aim, in the first instance, to account for the intentionality of desire. (See, for example, Papineau (1993).) There are also theories that try, in the first instance, to account for the intentionality of representational states more basic than propositional attitudes. (See, for example, Fodor (1989).) For all I say, such theories may accommodate or may easily be supplemented or modified to accommodate credences very well-but how well will be a question for another day.

${ }^{2}$ Harman (1986) and Pollock (2006) hold that credence talk is replaceable by binary belief talk about objective probabilities (24; 94). Christensen (2004) and Frankish (2009) argue against such a view (18-20; 77-78).
} 
credences seriously is compatible with a number of different views about binary belief. We may take credences seriously and hold that both the notion of credence and of binary belief have significant roles to play in the explanation and prediction of action and behaviour. Or we may endorse Richard Jeffrey's (1970) view that the notion of credence has 'sucked the marrow' out of our 'ordinary notion of belief', leaving the latter emaciated (172). Or we may go so far as to hold that there is no such thing as binary belief or that the very notion of binary belief is incoherent. I'll assume, however, that if the notion of binary belief is coherent, we can understand it in terms of one's credences, desires, and behavioural dispositions. ${ }^{3}$

In the next section, I'll go through an exemplar of a causal theory of intentionality and an exemplar of a teleological theory of intentionality, the former propounded by Stalnaker (1984) and the latter by Millikan (1989). In section 3, I'll argue that such theories are tailor-made to account for the intentionality of binary beliefs, but not credences. Hence, if you like the theories but also take credences seriously, you'll need to find ways to supplement your account of intentionality. In section 4, I'll consider some such ways and argue that they are unsatisfactory. In section 5, I'll offer some very natural ways of modifying the original theories to help them account for the intentionality of credences. But unfortunately, such modifications, which involve an appeal to objective probabilities, do not ultimately work. In section 6 , I conclude.

\section{Two Naturalistic Theories of Intentionality}

Intentional states like that of belief, desire, fear, and hope have certain contents. For example, one may believe that Copenhagen is the capital of Denmark or desire that the snowstorm will soon abate. In the first case, one is in a state of belief with the content 'Copenhagen is the capital of Denmark'. In the second case, one is in a state of desire with the content 'The snowstorm will soon abate'.

\footnotetext{
${ }^{3}$ It will take me beyond the scope of this paper to defend such an assumption in depth. But several philosophers do subscribe to it. See, for example, Weatherson (2005), Frankish (2009), and Fantl and McGrath (2009) (420; 76-77; 154).
} 
A naturalistic theory of intentionality aims to account for the intentionality of such states in purely naturalistic terms. Here is a crude example of such a theory: if $\mathrm{S}$ is in a state of believing that $p$, then the world being such that $p$ has caused $\mathrm{S}$ to be in such a state. The theory is simple. It's also naturalistic insofar as causation is naturalistic, and we can cash out in naturalistic terms what it is for a state to be a belief (rather than a desire or some other state). But the problem with the theory is that it does not allow for false beliefs. In what follows, I'll consider two significantly more sophisticated theories designed to avoid this problem.

\subsection{Stalnaker's Theory of Intentionality}

Stalnaker's causal theory of intentionality is a refinement of the crude theory we've just seen. According to Stalnaker (1984), belief is a kind of indication, and since indication can be spelt out in naturalistic terms, so can belief. Stalnaker illustrates what he means by 'indication' by appealing to an example involving tree rings. Under optimal conditions, the number of tree rings a tree has correlates with the age of the tree. A tree's having ten tree rings indicates that it is ten years old just because it is in a state that, under optimal conditions, it is in only if and because it is ten years old. Analogously, Stalnaker holds that ' $[\mathrm{w}] \mathrm{e}$ believe that $p$ just because we are in a state that, under optimal conditions, we are in only if $p$, and under optimal conditions, we are in that state because $p$, or because of something that entails p' (18). ${ }^{4}$ Unlike the crude theory sketched earlier, Stalnaker's theory allows for false beliefs. A tree with $x$ tree rings may indicate its age incorrectly as long as, under optimal conditions, it has $x$ tree rings only if and because the tree is $x$ years old. Similarly, we may believe that $p$ even if not- $p$ as long as, under optimal conditions, we believe that $p$ only if $p$ and because $p$.

But what are optimal conditions with respect to beliefs? Stalnaker (1984) does not say what they are exactly, but he writes:

It is $[\ldots]$ intuitively clear $[\ldots]$ that there is a presumption that peo-

\footnotetext{
${ }^{4}$ Stalnaker's theory is similar to and inspired by Stampe's (1977).
} 
ple's beliefs will correlate with, and be caused by, their environments. Where beliefs are false, or only accidentally true, we also expect some explanation for the deviation from the norm: either an abnormality in the environment, as in optical illusions or other kinds of misleading evidence, or an abnormality in the internal belief-forming mechanisms, as in wishful thinking or misremembering. These intuitions suggest that we do have the conceptions of normal or optimal conditions which make it possible to understand belief as a kind of indication. (19)

From the quote, Stalnaker seems to take 'optimal' to mean 'epistemically optimal'. For example, suppose I believe that there's a pond to my right. On Stalnaker's theory, if my belief is false, it is because conditions are less than epistemically optimal. There may be something abnormal in my belief-forming mechanisms or something misleading about my evidence. Perhaps I'm not paying enough attention to my surroundings, or I'm not wearing my glasses. Perhaps someone has built a fake pond to my right or has put up mirrors all over the place to confuse people. According to Stalnaker, I still count as believing that there's a pond to my right as long as, under optimal conditions, I'm in such a state only if and because there's a pond to my right.

\subsection{Millikan's Theory of Intentionality}

Whereas Stalnaker offers us a theory of intentionality in causal terms, Millikan (1989) offers us a theory of intentionality in teleological terms. Certain parts and systems of an animal have important teleological functions - functions that the animal has evolved to have and the successful performance of which confers evolutionary benefits upon the animal or has conferred such benefits upon its ancestors. For example, the heart has the function of pumping blood, whereas the vomiting reflex has the function of flushing poison out of an animal's body. Such functions, if performed successfully, will tend to confer evolutionary benefits upon the animal and contribute to its survival or to the propagation of its species. 
For some animals, there will be functions the successful performance of which requires the animal to represent certain things about the world correctly. For example, consider a frog's ingestive system, which has the function of ingesting food. For it to be able to perform this function, it is important that the frog's visual system be able to represent correctly the presence of a fly. If a fly comes near the frog, and its visual system represents it as a fly, that will result in the frog snapping at the fly, enabling its ingestive system to perform the function of ingesting food. But suppose a fly comes near the frog but its visual system fails to represent it as a fly. Or suppose that a small speck of dust floats near the frog, and the frog snaps at it because its visual system incorrectly represents it as a fly. In such cases, the frog's ingestive system has failed to perform its function.

Now, suppose a small black object comes near the frog. Its visual system comes to have a certain representation of the object, and its ingestive system makes use of such a representation in an attempt to perform its function of ingesting foodin response to the visual representation, the frog snaps at the small black object. Using Millikan's terminology, the frog's ingestive system is a consumer of the visual representation. And whatever content the representation has is to be explained in terms of the consumer's function - if the visual representation is a representation as of a fly, that is precisely because the condition in which a fly is present would enable the ingestive system to perform its function of ingesting food successfully.

Similarly, Millikan thinks that what content a belief has is to be explained in terms of the function of the belief's consumer. In particular, Millikan (1989) holds that if $\mathrm{S}$ believes that $p$, there is a consumer - perhaps S's ingestive system - that makes use of such a belief to perform its function. And there is a certain condition, namely, one in which the belief is true, that would allow the function to be performed successfully. Or, to use Millikan's terminology, there is 'a certain condition $[p]$ that would be normal for performance of the consumer's function', where a normal condition is one that explains the successful performances of the function on those occasions when it was performed, either by S itself or by S's ancestors, and such 
performances are part of the reason for S's existence and survival (287). ${ }^{5}$ Such a condition also gives us the content of the belief.

Suppose, for example, that $\mathrm{S}$ has a certain belief. And suppose that this causes $\mathrm{S}$ to move to the right to try to fulfil its ingestive system's function of ingesting food. In such a case, there is a certain condition, namely, one in which there's food to S's right, that will allow its ingestive system to successfully perform its function. Using Millikan's terminology, this condition is a condition that would be normal for the ingestive system's function of ingesting food. And this condition is also the content of S's belief. S moves to the right because it believes that there's food to the right, and the truth of its belief would enable its ingestive system to perform its function successfully.

Of course, S's belief may well be false. Conditions may not be normal, and if S turns right, its ingestive system may be unable to perform its function of ingesting food. S still counts as believing that there's food to its right because, under normal conditions, there would be food to its right, and $\mathrm{S}$ or its ancestors would have been able to make use of such a belief to perform the function of ingesting food. ${ }^{6}$

\section{Tailor-Made for Binary and Full Beliefs}

Stalnaker and Millikan attempt to provide naturalistic theories of intentionality in causal or teleological terms. But can their theories account for the intentionality of credences? This question has received scant attention, but it's a question worth asking if we take credences seriously. ${ }^{7}$ In this section, I'll show that,

\footnotetext{
${ }^{5}$ Millikan sometimes capitalises the word 'normal' to emphasise that she does not take it to mean statistically 'typical or average or even, in many cases, at all common' (285). She holds that what counts as statistically normal depends on which reference class we happen to pick, whereas 'the notion of semantic content clearly is not relative, in this manner, to arbitrary parameters' (ibid., 281).

${ }^{6}$ Dretske (1988), like Millikan (1989), cashes out his theory of intentionality by invoking the notion of functions. Although there are important differences between the two theories, they are not important for the purpose of discussing whether the theories can accommodate credences, and what I say about Millikan's theory with respect to credences should apply mutatis mutandis to Dretske's theory.

${ }^{7}$ Eric Schwitzgebel (2009) did ask, 'If (simplifying a bit) the belief that a cow is there is just the belief apt to be caused, in normal circumstances, by a cow's being there, what are we to say about the belief, with 0.4 degree of confidence, that a cow is there?' (271).
} 
as they stand, the foregoing theories are unable to accommodate credences and are tailor-made to account either for the intentionality of binary beliefs or for that of full beliefs (where to have a full belief that $p$ is to be certain that $p$ ). ${ }^{8}$

Presumably, both Stalnaker's and Millikan's theory are meant to apply to binary beliefs and not to credences in general. It would be extremely implausible, for instance, to read either as saying that, under optimal or normal conditions, if our credence in $p$ is 0.01 , then $p$ is true. If anything, one would expect that under such conditions, $p$ would be false.

One may suggest, however, that the theories be adapted to accommodate credences that meet a certain threshold. Consider the following:

Stalnaker* For any $p$ and any $x$ no less than a certain threshold, our credence in $p$ is $x$ just because we are in a state that, under optimal conditions, we are in only if $p$, and under optimal conditions, we are in that state because $p$, or because of something that entails $p$.

Millikan* For any $p$ and any $x$ no less than a certain threshold, if our credence in $p$ is $x$, then there is a condition $p$ that would be normal for the performance of its consumer's function.

If we set the threshold at a value greater than 0.5 , the theories will avoid the implausible consequence that, under optimal or normal conditions, if one has a credence less than 0.5 in $p$, then $p$ is true.

But a problem remains for both Stalnaker* and Millikan*. Consider a credence of 0.7 in $p$ and a credence of 0.8 in $p$. Since these are two different credal states, an account of intentionality shouldn't treat them as if they are the same. But both Stalnaker* and Millikan* fail to distinguish between the two sufficiently.

First, consider Stalnaker*. According to it, assuming that the relevant threshold is greater than 0.5 , both a credence of 0.7 in $p$ and a credence of 0.8

\footnotetext{
${ }^{8}$ Sometimes the term 'full belief' is used interchangeably with the term 'binary belief'. But I'll use the two terms differently. One may have a binary belief that $p$ without having a full belief that $p$ in the sense that one may believe that $p$ without being certain of it.
} 
in $p$ indicate that $p$. That is, under optimal conditions, each credal state obtains only if $p$ and because $p$ (or because of something that entails $p$ ). But this doesn't distinguish between the two different credal states sufficiently. Stalnaker's original theory supposedly reflects the 'presumption that people's beliefs will correlate with, and be caused by, their environments', in particular, the presumption that a belief that $p$ will correlate with and be caused by the world being such that $p$ (19). But insofar as there is a presumption of a correlation between a credence of 0.7 in $p$ and the world being such that $p$, and a correlation between a credence of 0.8 in $p$ and the world being such that $p$, there should also be a presumption that the second correlation is stronger than the first. Yet this presumption is not reflected in Stalnaker*.

Also, insofar as there is a presumption that a credence of $x$ in $p$ is caused by the environment, it seems that the presumption should be that such a credence is caused, not by the world being such that $p$, but by it being such that the objective probability of $p$ being true is $x$. (More on this idea in section 5.) For example, suppose that conditions are epistemically optimal, and we have a credence of 0.7 in a particular radioactive atom decaying in the next hour. Insofar as such a credence is caused by the environment, it seems that it's caused by the world being such that the objective probability that the atom will decay in the next hour is 0.7 , and not by it being such that the atom will in fact decay in the next hour. This in turn suggests that a credence 0.7 in $p$ and a credence of 0.8 in $p$ should be presumed to have different causes. Pace Stalnaker*, they shouldn't both be presumed to be caused by the world being such that $p$.

Second, consider Millikan*. Suppose that the relevant threshold is 0.5. And suppose S's ingestive system makes use of S's credences to perform its function of ingesting food. According to Millikan*, whether S has a credence of 0.7 or a credence of 0.8 in there being food to the right, the condition that would be normal for the performance of such a function is one in which there is food to the right. Or to put the point another way, so long as $p$ is true, it doesn't matter for the purpose 
of ingesting food whether $\mathrm{S}$ has a credence of 0.7 or a credence of 0.8 in there being food to the right. But it seems that it should matter given that the two credences are different credal states (even though they have the same content). Otherwise, it is hard to see why there should be a need for credences of different strengths at all.

Note also that so long as S's credence in there being food to the right is less than 1 , then even if there's no food to the right, S's ingestive system might still be able to perform its function of ingesting food successfully. We know from decision theory that betting on a less likely event may sometimes have greater expected utility than betting on a more likely event. If we proceed to bet on the less likely event, its occurrence will lead to a better outcome for us (utility-wise) than the occurrence of the more likely event. Similarly, when $\mathrm{S}$ has a credence of 0.7 that there's food to the right, it might still move to the left. For even though $\mathrm{S}$ has a small credence that there's food to the left, it may have high credence that whatever food might be found there will be vastly more nutritious and desirable than food to the right. So it might take a calculated risk and go left. In such a case, supposing that either there is food to the right or to the left but not both, there not being food to the right will actually be normal for the performance of S's ingestive system. That is, the presence of food to the left rather than to the right will enable $\mathrm{S}$ to successfully ingest food. Now, it's possible that if S's credence in there being food to the right goes up to 0.8 , the risk of moving to the left will no longer be worth taking, in which case S might move to the right instead. In such a case, there being food to the right will be normal for the performance of S's ingestive system. The upshot is that when $S$ has a credence of $x$ in $p$, whether $p$ is normal for the performance of the relevant consumer's function depends on what $S$ does given the credence it has. When $x$ is 1 , there is no question as to what $\mathrm{S}$ would do-it would act on $p$ being true. But this need not be so when $x$ is less than 1 .

It is clear that the above problems do not arise for the original theories put forward by Stalnaker and Millikan. They also do not arise if we wish to use the theories to account for the intentionality of full beliefs (i.e., states of certainty). 
Take, for example, Stalnaker's theory and read it as follows: we are certain that $p$ just because we are in a state that, under optimal conditions, we are in only if $p$, and under optimal conditions, we are in that state because $p$, or because of something that entails $p$. This reading of the theory is not vulnerable to the above problem raised for Stalnaker*.

However, if we take credences seriously, the following question arises: how may someone sympathetic to the theories put forward by Stalnaker or Millikan account for the intentionality of credences? Since the theories, as they stand, can't provide such an account, their proponents will either need to supplement them or modify them in a way that avoids the worries faced by Stalnaker* and Millikan*. How may they do so?

\section{Supplementing the Theories}

I'll first consider how Stalnaker's and Millikan's original theories may be supplemented to account for the intentionality of credences. Three views will be discussed. First, one may suggest that we first account for the intentionality of beliefs via one of the two theories and then exploit the functionalist relations that stand between beliefs and credences to account for the intentionality of credences. Second, one may suggest that we provide a disparate or independent account of the intentionality of credences. Third, one may suggest that, to account for the intentionality of credences, we simply suppose counterfactually that they were full beliefs. I'll elaborate on the views below.

\subsection{Exploiting Functionalist Relations}

Set aside credences for the time being. How may we provide a naturalistic account of the intentionality of desires? As they stand, the theories discussed above are silent on this issue. But this is surely not a problem for them. Perhaps we just need to supplement the theories by exploiting a broadly functionalist idea 
concerning how one's beliefs, desires and behavioural dispositions are related. ${ }^{9}$ To illustrate how this might work, consider the following toy example.

A creature often faces a choice between pressing the left button and pressing the right button. It believes that, in all cases, it'll get food if and only if it presses the left button. Suppose it presses the left button and makes a similar decision every time it faces a similar choice. Now, suppose we have a naturalistic account of the intentionality of binary beliefs, and for simplicity, suppose that desires are allor-nothing. Given the functionalist view that the creature's beliefs, in combination with its desires, drive it to make the choices that it makes, it is plausible to hold that it desires to get food. For, according to such a view, to desire to get food is just to be in a state that disposes it to act in such a way given such beliefs. Given a naturalistic account of the intentionality of beliefs and given that functionalist relations can be cashed out in naturalistic terms, we have a naturalistic account of the intentionality of desires.

May we account for the intentionality of credences in a similar way? One may suggest the following strategy. First, give an account of the intentionality of beliefs by appealing to either Stalnaker's or Millikan's theory. This allows us to break out of the intentional circle. Second, once we've broken out of the circle, appeal to the functionalist relations that stand between our beliefs and our credences to account for the intentionality of the latter. ${ }^{10}$

The suggested strategy can't work in general. Suppose that S's standards for belief are extremely high: although there are many propositions to which she assigns intermediate credences, there are relatively few propositions in which she has a high enough credence for her to count as adopting an attitude of binary or full belief towards them. Hence, to account for the intentionality of S's credences, the strategy under consideration can't get very far off the ground. For, according to it, we should first break out of the intentional circle by appealing to Stalnaker's

\footnotetext{
${ }^{9}$ For example, see Stalnaker (1984) (19).

${ }^{10}$ For example, if we know that $\mathrm{S}$ is rational and believes that the chance that $p$ is true is 0.7 , it may be reasonable to infer that she has a credence of 0.7 in $p$. Cf. Lewis's Principal Principle (Lewis 1980).
} 
or Millikan's theory to account for the intentionality of S's binary or full beliefs. But, by hypothesis, S hardly has any such beliefs. Even if we employ Stalnaker's or Millikan's theory to account for the intentionality of the few beliefs she might have (if any at all), it'll be hard to make use of such beliefs as a springboard to account for the intentionality of all her credences. For the very few beliefs the agent has surely underdetermines her vast number of credences.

One may wonder why we should worry about a creature like S. Perhaps real-life creatures have many binary or full beliefs, and we should be content if we can use their beliefs as a springboard to account for the intentionality of their credences. But if a creature like $\mathrm{S}$ is possible, then there must be some way to account for the intentionality of her credences that does not appeal to binary or full beliefs. If there's such an account, however, we should be able to deploy it to account for the intentionality of our credences. Our having binary or full beliefs in addition to intermediate credences shouldn't render the account inapplicable to us. But then, given such an account, there'll be no need to appeal to binary or full beliefs to account for the intentionality of our credences in the first place. We may simply bypass Stalnaker's and Millikan's theories.

Now one may point out that in the toy example above, we appealed to both beliefs and behaviour to account for the intentionality of desires. So why not do something similar in the case of credences? One may suggest that when $\mathrm{S}$ has very few binary or full beliefs, we may still be able to account for the intentionality of her credences by appealing to her desires and behaviour as well. However, adopting the suggestion is tantamount to abandoning the original strategy. Suppose, to make the point vivid, that $\mathrm{S}$ has no binary or full beliefs. Then, insofar as we can tell what her credences are by looking at her desires and behaviour, it is really the appeal to her desires and behaviour, rather than to her beliefs, that does the heavy lifting. In such a case, we are no longer depending on Stalnaker's or Millikan's theory as a springboard to help us account for the intentionality of S's credences. Instead, we are appealing to some other account altogether. This brings us to the second view 
regarding how to supplement Stalnaker's and Millikan's original theories.

\subsection{A Disparate Account of the Intentionality of Credence}

As mentioned earlier, Stalnaker's and Millikan's theories do not in themselves say anything about the intentionality of desire. And this need not be a problem for the theories as they stand. To deal with desires, we may supplement the theories by exploiting a broadly functionalist idea concerning how one's beliefs, desires and behavioural dispositions are related. Or perhaps we may just give a disparate account of the intentionality of desire. After all, one might think that although beliefs and desires are intimately related, they are still two different kinds of mental state. So it might not be surprising if we need to treat them very differently insofar as we wish to account for their intentionality.

Might we have to adopt a similar strategy when it comes to the intentionality of belief and that of credence? Might we just have to come up with disparate accounts of their intentionality? Here's a prima facie reason for thinking that the answer is 'no'. Belief and desire are rather different beasts, even though intimately related. So it may not be surprising if they require different treatments, insofar as the project of naturalising intentionality is concerned. But given that belief and credence are both doxastic attitudes - and given the assumption that the former is reducible to the latter (or to the latter plus other non-doxastic states) - a unified account of their intentionality seems desirable.

Admittedly, it's possible that even though binary beliefs or full beliefs (credences of 1) are reducible to (intermediate) credences, they still have a special status relative to the latter, and this explains why they require very different treatment from the latter insofar as accounting for intentionality is concerned. ${ }^{11}$ I have nothing to say that will rule out such a possibility. But, as a matter of fact, several available accounts of the intentionality of credence that make no appeal to Stalnaker's or Millikan's theory will, if successful, also be able to account for the intentionality

\footnotetext{
${ }^{11}$ Thanks to an anonymous referee for pressing this concern.
} 
of binary or full belief easily. And while appealing to such accounts may not show that Stalnaker's or Millikan's theory is false, it does render them redundant.

Consider interpretivist or functionalist theories of intentionality, which actually seem tailor-made for credences. For example, David Lewis (1974) attempts to cash out the intentionality of both our beliefs and desires at the same time by appealing to principles such as the Rationalization Principle, according to which the beliefs and desires we ascribe to an agent 'should be such as to provide good reasons for his behavior' (337). ${ }^{12}$ What counts as good reasons, according to Lewis, is to be spelt out in 'decision-theoretic terms'; in particular, he takes beliefs and desires to come in degrees, and holds that, given an agent's behaviour, the credences and utilities (degrees of desire) of the agent are those for which the behaviour in question has maximum expected utility - or an expected utility no less than any other possible behaviour (ibid.).

Relatedly, consider representation theorems in Bayesian decision theory. According to such theorems, if your preferences satisfy certain constraints (such as transitivity, connectedness, etc.), then you can be represented - or interpreted - as having preferences that maximise expected utility relative to some credence and utility functions. ${ }^{13}$ If we understand your preferences in terms of your choice behaviour (or behavioural dispositions having to do with what choices to make), then the basic idea is that we can rationalise your choice behaviour (or behavioural dispositions) by attributing to you various credences and utilities. The contents of your credences and utilities are whatever will help us make decision-theoretic sense of your behaviour.

The theories above attempt to give us the contents of our credences and utilities in a package deal. Suppose something along the lines of the theories is correct. Then we have an account of the intentionality of credences-including credences of value 1 -that doesn't appeal to Stalnaker's or Millikan's theory. Furthermore,

\footnotetext{
${ }^{12}$ See also Donald Davidson (1985).

${ }^{13}$ See, for example, Maher (1993) (9). For Ramsey's classic presentation of his representation theorem, see Ramsey (1990/ 1927).
} 
given that belief can be cashed out in terms of credences, desires, and behavioural dispositions, the theories will also give us an account of the intentionality of belief. Again, this does not show that Stalnaker's or Millikan's theory is false per se. But suppose we employ something like Lewis's theory to account for the intentionality of credences, and such a theory, if successful, will also account for the intentionality of binary or full beliefs. Then we'll simply have no need for Stalnaker's or Millikan's theory at all. ${ }^{14}$

\subsection{Going Counterfactual}

Instead of trying to exploit functionalist relations between belief and credence, and instead of trying to come up with disparate theories of the intentionality of belief and of that of credence, one may suggest the following. Simply hold that an agent's credence of $x$ has the content $p$ if and only if the following counterfactual holds: if that credal state the agent is in were a state of binary or full belief, it would be a state of believing or fully believing that $p$. If either Stalnaker's or Millikan's theory can account for the intentionality of binary or full beliefs, then, given that counterfactuals can be understood in naturalistic terms, we'll have a naturalistic account of the intentionality of credences. Or so the thought goes.

The suggestion is reminiscent of J.T. Whyte's (1990) defence of success semantics against the charge that it is unable to handle credences; showing why his defence is unsatisfactory will help show why the suggestion under consideration is unsatisfactory too. According to success semantics, a 'belief's truth condition [content] is that which guarantees the fulfilment of desire by the action which that belief and desire would cause' (Whyte, 1990, 150). If Whyte is right, then given a naturalistic account of the intentionality of desire, success semantics yields a naturalistic account of the intentionality of belief. But Whyte's account doesn't fare too well in

\footnotetext{
${ }^{14}$ Admittedly, we haven't ruled out the possibility of a theory that accounts for the intentionality of credence without accounting for the intentionality of binary or full belief. But suppose someone thinks that intermediate credences require different treatment from binary or full beliefs. Given what has been said above, the onus is on her to show that an account of the intentionality of credence won't render a disparate account of the intentionality of binary or full beliefs redundant.
} 
dealing with the intentionality of credence. For example, if $\mathrm{S}$ has a credence of 0.5 in $p$, she may well act in a way that best satisfies her desires if $p$ were in fact false. In response, Whyte (1990) holds that success semantics, as it stands, applies only to full beliefs. (Whyte also uses the term 'full belief' to refer to a state of certainty.) But he thinks that this is not a problem even if we hardly have any full beliefs- he thinks that we may still cash out the contents of partial beliefs in naturalistic terms by holding that '[a partial] belief's truth condition [content] is that which suffices for the success of the actions it would cause if it were a full belief' (Whyte 1990, 156; Whyte's emphasis). ${ }^{15}$

Whyte's response is unsatisfactory. First, it's not even clear that the antecedent of the relevant counterfactual makes sense. ${ }^{16}$ For to suppose that a state of partial belief were a state of full belief seems to be to suppose something impossible. Since being in a state of having a credence of 0.7 in $p$ essentially requires one to have a credence of 0.7 in $p$, there's no possible world in which such a state were a state of full belief.

Second, a naturalistic theory of intentionality should explain in naturalistic terms why certain states have any content at all. For instance, according to Stalnaker (1984), a belief state has content because of some kind of causal relation that, under optimal conditions, would obtain between the subject of the belief and the world. But Whyte fails to account for why a state of partial belief has content. To account for the intentionality of a partial belief, Whyte tells us to suppose that it were a full belief. Presumably, we are to consider a full belief with the same content as the partial belief, or we will have no reason to hold that whatever guarantees the success of the actions that the full belief would cause is the content of the partial belief. But such a move presupposes that the partial belief is contentful without explaining why it is so. ${ }^{17}$ Or, to put the point another way, for Whyte's account of the intentionality of partial belief to be informative, he should be able to tell us

\footnotetext{
${ }^{15}$ Philosophers who endorse Whyte's defence include Papineau (1993) and Dokic and Engel (2005) (74;9).

${ }^{16} \mathrm{I}$ 'm grateful to an anonymous referee for raising this point.

${ }^{17}$ This point is made in Tang (forthcoming).
} 
what full belief a partial belief would have been if it had been a full belief, without presupposing that the partial belief has a particular content. But he hasn't done that.

For similar reasons, we shouldn't try to account for the intentionality of an agent's intermediate credence in $p$ by invoking the counterfactual that if such a credence were a binary or full belief, then the agent would have a binary or full belief that $p$. First, it's hard to make sense of the antecedent of such a counterfactual. And second, such an account fails to be informative.

To sum up, the theories of intentionality put forward by Stalnaker and Millikan are unable to account for the intentionality of credences. This isn't necessarily a problem for the theories (unless we hold that the notion of binary belief is incoherent). However, proponents of the theories who take credences seriously will still need to find a way to supplement their account of intentionality to accommodate credences. One way to try to do so is by exploiting the idea that credences and binary or full beliefs are functionally related. Another is to provide a disparate account of the intentionality of credences. A third way is to hold that the intentionality of one's partial belief can be accounted for by supposing that it were a binary or full belief. I've argued above that all three approaches are unsatisfactory. The first approach has problems dealing with creatures that have no or very few binary and full beliefs. The second threatens to render Stalnaker's and Millikan's theories redundant. The third fails to be sufficiently informative. Given this, it's worth exploring whether we may modify the original theories in a way that stays true to their spirit while enabling them to accommodate credences. In the next section, I'll consider some natural ways of making such a modification.

\section{Modifying the Theories: an Appeal to Objective Probabilities}

The theories of intentionality offered by Stalnaker and Millikan attempt to forge a strong link between belief and truth under optimal or normal conditions. Thus it may be no surprise that, as they stand, they can't accommodate credences. 
For credences are not in general the kind of thing that can be true or false. It does not make sense, for example, to say that a credence of 0.5 that it rained this morning is true or false.

But though credences are neither true nor false, one may think that the analogue of truth for credence is objective probability of some sort (Hájek, ms.). One may then think that, under optimal or normal conditions, a credence in $p$ is matched by the objective probability that $p$ is true, and suggest that we modify the theories of intentionality offered by Stalnaker and Millikan as follows:

Stalnaker + For any $p$ and any $x$ in $[0,1]$, our credence in $p$ is $x$ just because we are in a state that, under optimal conditions, we are in only if the objective probability that $p$ is true is $x$, and under optimal conditions, we are in that state because the objective probability that $p$ is true is $x$, or because of something that entails that the objective probability that $p$ is true is $x$.

Millikan + For any $p$ and any $x$ in $[0,1]$, if our credence in $p$ is $x$, then there is a condition, namely, one in which the objective probability that $p$ is true is $x$, that would be normal for the performance of the relevant consumer's function.

The suggestion is a very natural one. The modified theories appear to keep to the spirit of the original theories, the main difference between the two being that the original theories require a match between belief and truth under optimal or normal conditions, whereas the modified theories require a match between credence and objective probability under optimal or normal conditions. The modified theories also provide a unified account of the intentionality of partial belief and full belief. To account for the intentionality of one's partial belief, we don't have to rely on one having enough binary or full beliefs. Neither do we have to appeal to counterfactual scenarios in which partial beliefs were full beliefs. In addition, an account of the intentionality of binary belief falls out from the theories if to have a binary belief that $p$ is just to have a sufficiently high credence in $p$. Given all of this, the theories are worth exploring further. 
Unfortunately, the modified theories do not ultimately work. For them to work, there should always be a match between credences and objective probabilities under optimal or normal conditions. But such a match is not always available, whether we are talking about some sort of physical probability or some sort of epistemic probability. ${ }^{18}$ There are cases in which, under optimal or normal conditions, one's credence in $p$ is $x$, but it is false that the objective probability that $p$ is true is $x$.

\subsection{An Appeal to Physical Probability}

Stalnaker + and Millikan + each faces a problem if physical probabilities are invoked, whether we are talking about objective chances, propensities, or relative frequencies. ${ }^{19}$

To use an example from Patrick Maher (2006), suppose we are about to toss a coin that is either two-headed or two-tailed, but we do not know which (134-135). Assume that the coin will land on either of its two faces (and not on its edge, for example). In such a case, it's plausible that our credence in the coin landing heads is 0.5 . However, the physical probability of the coin landing heads - whether such probability is understood to be relative frequency or propensity or objective chance - is either 0 or 1 . For if the coin is two-tailed, it will land heads with a relative frequency or propensity or objective chance of 0 , and if it's two-headed, it will do so with a relative frequency or propensity or objective chance of $1 .{ }^{20}$ Now,

\footnotetext{
${ }^{18}$ For my purposes, any kind of probability that is not subjective probability counts as a kind of objective probability. Also, I prescind from issues regarding whether certain so-called probabilities (e.g. relative frequencies) really deserve to be thought of as probabilities. See Hájek (1997) for more on such issues.

${ }^{19}$ Certain problems may arise from the specific kind of physical probability invoked. For example, suppose that objective chance is invoked. On some views, the objective chance of a past event happening or of an event happening in a deterministic universe is either 0 or 1 (Lewis, 1980). This means that if we have an intermediate credence of $x$ in some past event happening or if our universe is deterministic and we have an intermediate credence of $x$ in some future event happening, there won't be a match between credence and objective probability. Now, it is implausible to claim that conditions are neither optimal nor normal in such cases. Having a partial belief that something in the past has happened, or living in a deterministic world and having a partial belief that some future event will happen does not mean that the environment is abnormal, or that our belief-forming mechanisms are not working properly, or that an organism can't make use of its (partial) beliefs to perform certain functions successfully.

${ }^{20}$ Maher's example was originally intended to show that credences cannot be understood as
} 
since there is no match between our credence and the relevant objective probability, a proponent of Stalnaker+ will have to hold that conditions are not optimal. But such a response is implausible for the following reason.

In the kind of case under consideration, there need not be 'an abnormality in the environment, as in optical illusions or other kinds of misleading evidence' (Stalnaker, 1984, 19). We may not have enough evidence to form a firm opinion about whether the coin will land heads, but to lack evidence is not to have misleading evidence. Neither need there be 'an abnormality in the internal belief-forming mechanisms, as in wishful thinking or misremembering' (Stalnaker, 1984, 19). In fact, our belief-forming mechanisms seem to be operating perfectly well when they assign a credence of 0.5 to the coin landing heads.

Now, it may be open to Stalnaker to claim that when conditions are epistemically optimal — when our belief-forming mechanisms are functioning properly and we are not presented with misleading evidence - our binary beliefs will often match the truth. But it is far less plausible to claim that our belief-forming mechanisms are not working properly or that we are presented with misleading evidence or suffering from illusions or hallucinations when our credences don't match the relevant objective probabilities. Granted, there may be 'a presumption that people's [binary] beliefs will correlate with, and be caused by, their environments' (Stalnaker, 1984, 19). But there isn't a presumption that their credences will track the relevant objective probabilities exactly. In fact, while it may be an epistemic ideal that all of one's beliefs be true, it is not an epistemic ideal that all of one's credences match the relevant objective probabilities. For an ideally rational and omniscient agent will presumably have extreme credences of 1 in all truths and 0 in all falsehoods. But given that there are various propositions whose objective probabilities of being

binary beliefs about physical probability. If credence talk can be replaced by talk of binary beliefs about objective probabilities, we should always be able to match credences with (believed) objective probabilities. But such a match is not always available: there are cases in which someone's credence in $p$ is $x$, but she believes that the objective probability that $p$ is true is not $x$. For instance, one's credence in the coin landing heads may be 0.5 , but if one believes that the coin is two-headed, one will presumably believe that the objective probability of the coin landing heads is not 0.5 . 
true are neither 0 nor 1 , it's false that such an agent's credences will match all the relevant objective probabilities.

There's also a problem for Millikan+ no matter which notion of physical probability is invoked. A match between our credences and the relevant objective probabilities is neither necessary nor sufficient for conditions to be normal - for conditions to be such as to allow certain functions to be performed successfully. To use an example from before, suppose that S's ingestive system makes use of its credences to perform the function of ingesting food. Suppose also that S has a credence of 0.7 in there being food to the right. According to Millikan+, there is a condition, namely, one in which the objective probability of there being food to the right is 0.7 , that is normal for the performance of the function of ingesting food. Or, in other words, Millikan+ has it that if the objective probability of there being food to the right is 0.7 , S's ingestive system will be able to make use of S's credence of 0.7 in there being food to the right to perform its function of ingesting food successfully.

But a match between S's credence and the relevant objective probability is not sufficient for S's ingestive system to perform its function successfully. Suppose that there is indeed food to the right and no food to the left. Suppose also that the objective probability of there being food to the right is 0.7. As mentioned earlier, S might well take a calculated risk - having a high credence that any food to the left will be much more nutritious and desirable than any food to the right, S may move to the left. In such a case, even though S's credence of 0.7 in there being food to the right matches the objective probability of there being food to the right, S's ingestive system will not be able to perform its function successfully.

A match between S's credence and the relevant objective probability is also not necessary for its ingestive system to perform its function successfully. Suppose, for instance, that the objective probability of there being food to the right is 0.75 , but S's credence in there being food to the right is 0.7. Suppose that based on such a credence, $\mathrm{S}$ moves to the right. Its ingestive system will successfully perform its 
function of ingesting food even though there isn't a match between credence and objective probability.

Granted, it may be that, all things being equal, a creature whose credences do not deviate too wildly from the relevant objective probabilities will tend to have a higher chance of survival than one whose credences deviate wildly from such probabilities. But the main point is as follows. While it may be plausible that the binary beliefs of a creature should match the truth for certain functions to be performed successfully, it is far less plausible that for certain functions to be performed successfully, its credences must match the relevant objective probabilities exactly. Yet this is what Millikan+ requires. ${ }^{21}$

\subsection{An Appeal to Epistemic Probability}

What if Stalnaker+ and Millikan+ invoke some kind of epistemic probability? Epistemic probabilities are conditional probabilities and can be thought to represent the degree of support that one proposition confers upon another. Given that epistemic probabilities are conditional probabilities and have their values as a matter of necessity, a mere appeal to epistemic probabilities isn't going to help account for the intentionality of unconditional credences - it's not clear which epistemic probabilities our unconditional credences are supposed to match under optimal or normal conditions.

Here's a suggestion. Perhaps we may hold that under optimal or normal conditions, our credence in $p$ will match the epistemic probability of $p$ conditional upon our total evidence. In the case in which a coin is either two-headed or twotailed, but we do not know which, it seems reasonable to hold that the epistemic probability that the coin will land heads given our total evidence is 0.5 . If we adopt

\footnotetext{
${ }^{21}$ It won't help to relax the requirement by holding that, under normal conditions, when a creature is $100 x \%$ confident that $p$, then the objective probability of $p$ being true does not deviate too wildly from $x$. Suppose that the objective probability of $p$ being true is 0.8 , and suppose that such a condition is normal for the performance of a creature's functions. Assume that an objective probability of 0.8 does not count as deviating too wildly from either a credence of 0.79 or a credence of 0.81 . In such a case, it's unclear whether $p$ give us the content of a credence of 0.79 or a credence of 0.81 , assuming that a creature has both credences.
} 
the suggestion, then assigning a credence of 0.5 to the coin landing heads will yield a match between our credence and the relevant epistemic probability.

Unfortunately, the suggestion runs into a problem. Suppose $q$ is our total evidence and we assign a certain credence to it. How do we account for the intentionality of such an attitude? Now, our credence in $q$ may either be less than 1 or equal 1. Given that $q$ is likely to be a contingent and far from self-evident claim, it seems that S's belief-forming mechanisms are working properly only if she is not absolutely certain that $q \cdot{ }^{22}$ So it seems that, under optimal conditions, our credence in $q$ will be less than 1 . But if our credence in $q$ is less than 1, there won't be a match between credence and epistemic probability. This is because the epistemic probability of $q$ given our total evidence is 1 (since $q$ is our total evidence, and the epistemic probability of $q$ given $q$ is 1 ).

Furthermore, a match between credence and epistemic probability is neither sufficient nor necessary for conditions to be normal - for reasons similar to why a match between credence and physical probability is neither sufficient nor necessary for conditions to be normal. Suppose $\mathrm{S}$ has a credence of 0.7 in there being food to the right, and the epistemic probability of there being food to the right given S's total evidence is 0.7. Suppose that there is indeed food to the right and no food to the left. Nonetheless, S may take a calculated risk and move to the left. In such a case, even though there is a match between credence and epistemic probability, S's ingestive system will not be able to perform its function of ingesting food successfully.

A match between credence and epistemic probability is also not necessary for S's ingestive system to perform its function successfully. Suppose, for instance that the epistemic probability of there being food to the right given S's total evidence is 0.75 , but S's credence in there being food to the right is 0.7 . Suppose that based on such a credence, $\mathrm{S}$ moves to the right. Its ingestive system will successfully perform its function even though there isn't a match between credence and epistemic

\footnotetext{
${ }^{22}$ Lewis (1986), for example, holds that it is not reasonable for agents like human beings to assign a credence of 1 to our evidence propositions. (585-587).
} 
probability.

\subsection{An Appeal to Calibration}

Stalnaker+ and Millikan+ are problematic whether they invoke physical probability or epistemic probability. Let me now turn to a slightly different way of modifying the original theories of intentionality. Suppose that a creature is in a state of having a credence of $x$ in $p$. Take the class of all cases in which conditions are optimal or normal, and the creature (or perhaps a creature like it) is in the same state. The content of the credence in question, one may suggest, is that which is true in $100 x \%$ of such cases. For example, if a creature has a credence of 1 in $p$, then $p$ is that which is true in all cases in which the creature is in the same state and conditions are optimal or normal. And if the creature has a credence of 0.7 in $p$, then $p$ is that which is true in $70 \%$ of the cases in which the creature is in the same state and conditions are optimal or normal. ${ }^{23}$

Call the view Calibration. ${ }^{24}$ There are things to be said in its favour. For instance, suppose you assign a credence of 0.7 to 'It rained this morning'. Then there seems to be a good sense in which your credence is the right credence to have - there's a good sense in which your belief-forming mechanisms are working optimally - only if $70 \%$ of the cases in which your belief-forming mechanisms lead you to assign a credence of 0.7 to 'It rained this morning' are cases in which it rained. ${ }^{25}$

But there's a problem for Calibration similar to that encountered by the

\footnotetext{
${ }^{23}$ Thanks to an anonymous referee for raising this suggestion.

${ }^{24}$ If the content of a credence of strength $x$ is true in $100 x \%$ of the relevant cases, then such a credence is perfectly calibrated with respect to those cases. For more on the notion of calibration, see van Fraassen (1983).

${ }^{25}$ Calibration is similar to - but not exactly the same as - a version of Stalnaker+ or Millikan+ that appeals to the notion of relative frequencies. Consider, for example, a version of Stalnaker+ that appeals to relative frequencies. According to it, under epistemically optimal conditions, if $\mathrm{S}$ has a credence of 1 in a coin landing heads, then the relative frequency of the coin landing heads is 1, i.e., the coin will always land heads. Now, consider Calibration. According to it, if $\mathrm{S}$ has a credence of 1 in a coin landing heads, then the coin will land heads in all cases in which $\mathrm{S}$ is in the same state and conditions are optimal or normal. This is consistent with the coin not landing heads sometimes, for example, in cases in which $\mathrm{S}$ does not have a credence of 1 in it landing heads.
} 
version of Stalnaker+ that appeals to physical probability. Consider a two-headed coin and suppose we don't know whether it's two-headed or two-tailed. Suppose we assign a credence of 0.5 to the coin landing heads. According to Calibration, the frequency of the coin landing heads relative to cases in which conditions are optimal or normal, and in which we assign a credence of 0.5 to the coin landing heads, equals 0.5. But since the coin is two-headed, all the cases in which we assign a credence of 0.5 to the coin landing heads will be cases in which the coin lands heads.

\section{Conclusion}

Suppose we wish to provide a naturalistic account of intentionality. Like several philosophers, we focus on the intentionality of belief. But if we take credences seriously, we should be able to extend or modify our account to deal with the intentionality of credences as well.

We've seen, however, that the theories put forward by Stalnaker and Millikan are tailor-made to account for the intentionality of binary or full beliefs. Given this, there's a question of how to supplement or modify such theories to account for the intentionality of credences. I've argued that some natural ways of doing so are unpromising. If I'm right, this spells trouble for Stalnaker's and Millikan's theories, and we have good reason to move towards some other theory of intentionality.

Acknowledgements: Thanks to audiences at the Australian National University and the National University of Singapore for discussion of the paper. Thanks to two anonymous referees for their very helpful feedback. And special thanks to Jens Christian Bjerring, Ben Blumson, Alan Hájek, and Wolfgang Schwarz for their very useful comments on the paper. 


\section{Works Cited}

Christensen, David (2004). Putting Logic in its Place: Formal Constraints on Rational Belief. New York: Oxford University Press.

Davidson, Donald (1985). 'A New Basis for Decision Theory'. Theory and Decision, $18,87-98$.

Dokic, Jérôme and Pascal Engel (2005). 'Ramseys Principle Revisited'. In Ramsey's Legacy. Ed. Hallvard Lillehammer and D. H. Mellor. New York: Oxford University Press.

Dretske, Fred (1988). Explaining Behavior: Reasons in a World of Causes. Cambridge, MA: MIT Press

Fantl, Jeremy and Matthew McGrath (2009). Knowledge in an Uncertain World. UK, Oxford: Oxford University Press.

Fodor, Jerry A. (1989). Psychosemantics. Cambridge, MA: MIT Press.

Frankish, Keith (2009). 'Partial Belief and Flat-Out Belief'. In Degrees of Belief. Ed. F. Huber and C. Schmidt-Petri. Dordrecht: Springer. 75-93.

Hájek, Alan (1997). "Mises Redux"—Redux. Fifteen Arguments Against Finite Frequentism', Erkenntnis, 45, 209-227.

Hájek, Alan (ms). 'A Puzzle about Partial Belief'.

Harman, Gilbert (1986). Change in View: Principles of Reasoning. Cambridge, MA: MIT Press.

Jeffrey, Richard (1970). 'Dracula Meets Wolfman: Acceptance vs. Partial Belief'. In Induction, Acceptance, and Rational Belief. Ed. Marshall Swain. Dordrecht, Holland: D. Reidel Publishing Company. 157-185.

Lewis, David (1974). 'Radical Interpretation'. Synthese, 23, 331-344.

Lewis, David (1980). 'A Subjectivist's Guide to Objective Chance'. In Studies in Inductive Logic and Probability, 2. Ed. Richard C. Jeffrey. Berkeley and Los Angeles: University of California Press. 263-293.

Lewis, David (1986). 'Probabilities of Conditionals and Conditional Probabilities II'. The Philosophical Review, 95, 581-589. 
Maher, Patrick (1993). Betting on Theories. USA, Cambridge: Cambridge University Press.

Maher, Patrick (2006). 'Review of Putting Logic In Its Place, by David Christensen'. Notre Dame Journal of Formal Logic, 47:1, 133-149.

Millikan, Ruth G. (1989). 'Biosemantics'. The Journal of Philosophy, 86, 281-297.

Papineau, David (1993). Philosophical Naturalism. UK, Oxford: Blackwell.

Pollock, John L. (2006). Thinking About Acting: Logical Foundations for Rational Decision Making. New York: Oxford University Press.

Ramsey, F. P. (1990) 'Truth and Probability'. In F. P. Ramsey. Philosophical Papers. Ed. D. H. Mellor. USA, NY: Cambridge University Press. (Paper written 1926)

Schwitzgebel, Eric (2009). 'A Phenomenal, Dispositional Account of Belief'. Nous, $36,249-275$.

Stalnaker, Robert C. (1984). Inquiry. Cambridge: MA: The MIT Press.

Stampe, Dennis W. (1977). 'Toward a Causal Theory of Linguistic Representation'. Midwest Studies in Philosophy, 2, 42-63.

Tang, Weng Hong. (Forthcoming). 'Success Semantics and Partial Beliefs'. The Journal of Philosophical Research.

van Fraassen, Bas. (1983). 'Calibration: A Frequency Justification for Personal Probability'. In Physics, Philosophy and Psychoanalysis. Eds. R. S. Cohen and L. Laudan. Dordrecht: D. Reidel Publishing Company, 295-319.

Weatherson, Brian (2005). 'Can We Do Without Pragmatic Encroachment?'. Philosophical Perspectives, 19, 417-443.

Whyte, J.T. (1990). 'Success Semantics'. Analysis, 50, 149-157. 